\title{
Modern Contraceptive Use among Orthodox Christian and Muslim Women of Reproductive Age Group in Bahir Dar City, North West Ethiopia: Comparative Cross Sectional Study
}

\author{
Damot Walelign', Alemtsehay Mekonen², Mastewal Netsere ${ }^{3}$, Molalign Tarekegn ${ }^{*}$ \\ ${ }^{1}$ Joint MPH Program, Bahir Dar University and GAMBY, Bahir Dar, Ethiopia \\ ${ }^{2}$ College of Medicine and Health Sciences, Bahir Dar University, Bahir Dar, Ethiopia \\ ${ }^{3}$ Organization for Rehabilitation and Development of Amhara, Sekotta, Ethiopia \\ ${ }^{4}$ College of Medical Sciences, GAMBY, Bahir Dar, Ethiopia \\ Email: ${ }^{*}$ tamolalign@gmail.com
}

Received 10 September 2014; revised 10 October 2014; accepted 6 November 2014

Copyright (C) 2014 by authors and Scientific Research Publishing Inc.

This work is licensed under the Creative Commons Attribution International License (CC BY). http://creativecommons.org/licenses/by/4.0/

(c) (7) Open Access

\section{Abstract}

Background: Mothers are dying as a result of abortion associated with preventable unintended pregnancy. The objective of this study was to compare the prevalence of Modern contraceptive use and associated factors among Muslim and orthodox Christian women of reproductive age group in Bahir Dar city. Methods: Comparative Cross-sectional study was carried out on 504 participants selected through Simple random sampling technique from the list of households. Data were collected through a pretested interviewer administered questionnaire. The data were analyzed using logistic regression model to determine odds ratio as a measure of strength off association. Result: The prevalence of modern contraceptive use was higher among Orthodox Christian women by 0.28 : $95 \%$ for the difference $(0.19,0.36)$. While $63.9 \%$ orthodox Christian women were using modern contraceptives only 36.1\% of Muslim women were using Modern contraceptive. Age, Religiosity and education level were found to have a statistical association for modern contraceptive use in Both Orthodox Christian and Muslim women ( $p$ value $<0.05$ ). Conclusion: The prevalence of modern contraceptive use among Muslim women was found to significantly lower than that in Orthodox Christian. Recommendation: More efforts should be done to increase the number of Modern Contraceptive users, by focusing on awareness creation on Modern contraceptives with special emphasis on Muslims.

\footnotetext{
"Corresponding author.
} 


\section{Keywords}

\section{Modern Contraceptive Use, Christian, Muslim, North West Ethiopia}

\section{Introduction}

Reducing the death of mothers in the process of giving birth by 2/3 was a global target for all nations worldwide [1]. However, the decline has been slow, stagnating or even reversing in many countries. Globally it is estimated that about 293,000 women died in 2013 as a result of pregnancy-related conditions [2]. Almost all maternal deaths (99\%) occur in developing countries, more than half of which occur in sub-Saharan Africa [3].

Unsafe abortion as a result of unintended pregnancy is the third major direct cause of maternal death next to severe bleeding/hemorrhage and infections responsible for $8 \%$ of maternal deaths worldwide [3] [4].

It is a major public health problem particularly in developing countries. Of 182 million pregnancies occurring every year, an estimated $36 \%$ are unplanned, and 20\% end in abortion [5].

The highest rate occurs in Sub-Saharan Africa, where about 86 unintended pregnancies occur for every 1000 women of reproductive age [6]. In Ethiopia, according to the 2011 EDHS, 25\% of women with births in the five years before the survey and 32\% of current pregnancies were reported as unintended [7].

Unintended pregnancy mainly results from the lack of, inconsistent, or incorrect use of effective contraceptive methods [8].

In Ethiopia even though an increase in the trend was observed for the past 10 years, the current contraceptive prevalence rate was very low (29\%) as compared to the target set by 2015. This would have its own share for the death of 676 mothers (per 100,000 live births) and 88 children per 1000 live births [7].

\section{Methods}

\subsection{Study Design}

A Community based comparative cross sectional study was conducted among Orthodox Christian and Muslim women of reproductive age.

\subsection{Study Area}

This study was conducted in Bahir Dar City, 565 km northwest of Addis Ababa, the capital of Ethiopia. The city has nine urban kebele administrations with a total population of 277,566 (135,441 are male and 142,125 Female) [9].

\subsection{Sample Size Determination and Sampling Method}

The sample size of the study was determined using Epi Info software based on Kelsey formula. The two sidedsignificance level (90\%), power (90\%), Sample size ratio (1), (35\%) outcome in Muslim (non exposure), (50\%) outcome in Christian and non response rate (10\%) was considered to come up with sample size of 252 for each group.

Proportional households were selected by Simple random sampling technique from the list in two randomly selected. From each sample household, a woman with in the reproductive age group was selected through lottery method. All Women in reproductive age group residing in Bahirdar town at least for the last six month were included in the study. However those who were critically sick, Pregnant and in postnatal period were excluded.

\subsection{Data Collection}

\section{Instrument and Procedure}

Current use of modern contraceptives was the dependent variable. It was measured interms of the use of one of the modern contraceptive methods during the data collection time.

A pretested interviewer administered questionnaire was employed to collect data. Four health extension workers were involved in data collection and one health professional was also recruited to closely supervise 
them. To assure its quality, the questionnaire was first prepared in English and then translated in to Amharic, training was given for data collectors and Supervisor, Supervision was carried out on daily bases and every day at the end of data collection questionnaires were reviewed and checked for completeness.

\subsection{Data Analysis}

At the end of data collection; it was cleaned, coded and entered in to SPSS version 16 statistical programs for analysis. Frequency and Percentages were calculated and used to describe the finding. To assess whether there is a significant difference in modern contraceptive use, difference between two population proportions with 95\% CI were done. In order to assess the importance of each independent variable, multiple logistic regression analysis models were employed. P-value of 0.05 was used as a cut of point for the level of significance and Odds ratio with $95 \%$ CI was used to measure the strength of the association.

\subsection{Ethical Considerations}

Ethical clearance was obtained from the Ethical Clearance Committee of GAMBY College of Medical Sciences and a letter of support was also obtained from the Regional Health Bureau to precede the study. Informed consent was obtained from participants before collecting the data to confirm their willingness to participate. Privacy and confidentiality was assured throughout the study.

\section{Result}

\subsection{Socio-Demographic Characteristics of Participants}

A total of 504 women of reproductive age group were interviewed giving a response rate of $100 \%$. Regarding the age, 122 (48.4\%) of orthodox Christian and 92 (36.5\%) of Muslim women were between the age group of 25 to 34. Majority of the respondents 198 (78.6\%) of orthodox Christian and 193 (76.6\%) of Muslim women were married. With regard to the educational status of the respondents, 35 (13.8\%) of orthodox Christian and 63 (25\%) of Muslim women were not attended any formal education. The assessment of occupational status showed that 94 (37.3\%) orthodox and 136 (54\%) Muslim women were housewives (Table 1).

\subsection{Reproductive and Other Characteristics of Participants}

As portrayed in Table 2, 49.6\% of orthodox and 39\% of Muslim respondents have 1 - 2 children. When their intension for the need to have additional children were assessed majority (54\%) Orthodox women need 3 - 4 children whereas majority of Muslims (50.4\%) wants to have 5 and above children. Regarding their sex preference, more than half of the study participants, 235 (93.3\%) orthodox Christian and 192 (76.2\%) Muslim women responded that sex of children is not their big problem. The decision for the number of children in majority of the orthodox Christian (91.4\%) and Muslim women (87.3\%) were decided by discussion with their partner. Almost all of the participants in both groups knew at least one modern contraceptive method. A decision regarding contraceptive use in both orthodox Christian and Muslim women reported as it was determined by discussion with their husband. With respect to religious service attendance, $72.2 \%$ orthodox Christian and $75.4 \%$ Muslim women were religious. Moreover in the impact of religious philosophy of women on contraceptive $58.3 \%$ of orthodox Christian and $75.8 \%$ of Muslim women describe that their religion does not allow contraceptive.

\subsection{Prevalence of Modern Contraceptive Use among Orthodox Christian and Muslim Women}

In this study 232 (91.7\%) orthodox Christian and 144 (57.1\%) Muslim women have ever used one form of modern contraceptive methods in their life. The current modern contraceptive use was $63.9 \%$ in orthodox Christian women and $36.1 \%$ in Muslim women. The difference for modern contraceptive use in Orthodox Christian women with $95 \%$ CI was $0.28(0.19,0.36)$. Majority of Modern contraceptive users, $62.9 \%$ orthodox Christian and $65 \%$ of Muslim women were using injectables. Regarding their intention about $84.5 \%$ of orthodox Christian and $57.1 \%$ of Muslim respondents reported as they have the intention to use modern contraceptives. The need to have more children was the most frequently mentioned reason for $31.2 \%$ orthodox women and $36.6 \%$ Muslim women (Table 3). 
Table 1. Socio-Demographic and Economic Characteristics of the respondents by religious Category, Bahir Dar, June, 2013.

\begin{tabular}{|c|c|c|c|c|}
\hline \multirow{2}{*}{ Variables } & \multicolumn{2}{|c|}{ Orthodox Christian } & \multicolumn{2}{|c|}{ Muslim } \\
\hline & Number & Percent & Number & Percent \\
\hline \multicolumn{5}{|l|}{ Age } \\
\hline $15-24$ & 83 & 32.9 & 87 & 34.5 \\
\hline $25-34$ & 122 & 48.4 & 92 & 36.5 \\
\hline $35-49$ & 47 & 18.7 & 73 & 29.0 \\
\hline \multicolumn{5}{|l|}{ Marital Status } \\
\hline Single & 54 & 24.4 & 59 & 23.4 \\
\hline Married & 198 & 78.6 & 193 & 76.6 \\
\hline \multicolumn{5}{|l|}{ Educational Status } \\
\hline Illiterate & 35 & 13.9 & 63 & 25.0 \\
\hline Primary (grade1 - 8) & 81 & 32.1 & 79 & 31.3 \\
\hline Secondary(>=grade 9) & 136 & 54.0 & 110 & 43.7 \\
\hline \multicolumn{5}{|l|}{ Occupation } \\
\hline Student & 17 & 6.7 & 26 & 10.3 \\
\hline GO/NGO Employed & 41 & 16.3 & 24 & 9.5 \\
\hline Merchant & 48 & 19.0 & 43 & 17.1 \\
\hline Daily laborer & 44 & 17.5 & 18 & 7.1 \\
\hline Unemployed & 102 & 40.2 & 141 & 56.0 \\
\hline \multicolumn{5}{|l|}{ Income } \\
\hline$<500$ & 27 & 10.7 & 33 & 13.1 \\
\hline $501-1000$ & 92 & 36.5 & 108 & 42.9 \\
\hline $1001-1500$ & 60 & 23.8 & 58 & 23.0 \\
\hline $1501-2000$ & 21 & 8.3 & 25 & 9.9 \\
\hline $2001-2500$ & 26 & 10.3 & 16 & 6.3 \\
\hline$>=2501$ & 26 & 10.3 & 12 & 4.8 \\
\hline \multicolumn{5}{|l|}{ Source of Family Income } \\
\hline Husband & 83 & 32.9 & 99 & 39.3 \\
\hline Wife & 22 & 8.7 & 14 & 5.6 \\
\hline Both & 126 & 50.0 & 107 & 42.5 \\
\hline Father and/mother & 21 & 8.3 & 32 & 12.7 \\
\hline
\end{tabular}

\subsection{Factors Associated with Modern Contraceptive Use among Orthodox Christian and Muslim Women}

Analysis of the independent variables in relation to the current use of contraceptive methods showed that religiosity, age and education were found to have significant association on contraceptive use ( $p$ value $<0.05$ ). On the contrary, the multiple logistic regression result did not show significant relationship between the dependent variable and some independent variables such as occupation, marital status, income, sex preference of children, desire more children, discussion with husband on contraceptive and decision on contraceptive use.

There was decreasing trend for using contraceptives as age increases. Those orthodox Christian women whose age was found between15 - 24 found to have statistically significant difference towards the use of modern contraceptives as compared to those in the age group of 35 - 49 AOR: 11.39, 95\% CI (3.03, 42.7) Similarly those Muslim women whose age was found between 15 - 24 found to have statistically significant difference towards 
Table 2. Reproductive Characteristics of the respondents by religious category, Bahir Dar, North West Ethiopia, June 2013.

\begin{tabular}{|c|c|c|c|c|}
\hline \multirow{2}{*}{ Variables } & \multicolumn{2}{|c|}{ Orthodox Christian } & \multicolumn{2}{|c|}{ Muslim } \\
\hline & Number & Percent & Number & Percent \\
\hline \multicolumn{5}{|l|}{ Total Living Children } \\
\hline 0 & 54 & 21.4 & 48 & 19.0 \\
\hline $1-2$ & 125 & 49.6 & 99 & 39.3 \\
\hline $3-4$ & 58 & 23.0 & 70 & 27.8 \\
\hline$>=5$ & 15 & 6.0 & 35 & 13.9 \\
\hline \multicolumn{5}{|l|}{ Number of Desired Children } \\
\hline $1-2$ & 54 & 21.4 & 24 & 9.5 \\
\hline $3-4$ & 136 & 54.0 & 101 & 40.1 \\
\hline$>=5$ & 62 & 24.6 & 127 & 50.4 \\
\hline \multicolumn{5}{|l|}{ Sex Preference } \\
\hline Have sex preference & 15 & 6.0 & 43 & 17.1 \\
\hline Sex Does not matter & 235 & 93.3 & 192 & 76.2 \\
\hline GOD/ALLAH knows & 2 & 0.8 & 17 & 6.7 \\
\hline \multicolumn{5}{|l|}{ Family Size Decision } \\
\hline Husband & 8 & 3.6 & 16 & 7.5 \\
\hline Wife & 11 & 5.0 & 10 & 4.7 \\
\hline Both & 203 & 91.4 & 187 & 87.8 \\
\hline \multicolumn{5}{|c|}{ Decision to Use Contraceptive } \\
\hline Husband & 11 & 5.0 & 10 & 4.7 \\
\hline Wife & 41 & 18.6 & 31 & 14.6 \\
\hline Both & 169 & 76.5 & 172 & 80.8 \\
\hline \multicolumn{5}{|l|}{ Religiousity } \\
\hline Religious & 182 & 72.2 & 190 & 75.4 \\
\hline Less religious & 70 & 27.8 & 62 & 24.6 \\
\hline \multicolumn{5}{|l|}{ Religious Permission } \\
\hline Yes & 2 & 0.8 & 2 & 0.8 \\
\hline No & 147 & 58.3 & 191 & 75.8 \\
\hline Don’t know & 103 & 40.8 & 57 & 23.4 \\
\hline
\end{tabular}

the use of modern contraceptives as compared to those in the age group of 35 - 49 AOR: 5.30, 95\% CI (1.46, 19.19).

The finding has also shown that there is significant difference between religious and less religious women with regard to modern contraceptive use. Compared with religious women, less religious women were about 5.56 times more likely to use modern contraceptive (AOR: 5.56, 95\% CI $(1.4,21.3)$ ) in Orthodox Christian women and 5 times more likely to use modern contraceptives in Muslim women (AOR: 5, 95\% (1.9, 14.8)).

The results of the study also showed that women's literacy status significantly associated with contraceptive use: women who have attended secondary education and above were illiterate women were 6.25 (AOR: 6.25, 95\% CI $(1.2,33.3)$ ) and 16.7 (AOR: $16.7,95 \%$ CI $(4.5,50)$ ) more likely to use modern contraceptives as compared to those who are illiterate in Orthodox Christian and Muslim women respectively (Table 4).

\section{Discussion}

Of 504 participants participated in the current study, majority 237 (47\%) had a desire for having three to four children. This was similar with the report of EDHS 2011 [7]. However difference was observed in the proportion of women who wants to have three to four children. While, 136 (54.0\%) Orthodox Christian women has the 
Table 3. Respondents knowledge and practices of contraceptive Method by religious category, Bahir Dar City, North West Ethiopia, June, 2013.

\begin{tabular}{|c|c|c|c|c|}
\hline \multirow{2}{*}{ Variables } & \multicolumn{2}{|c|}{ Orthodox Christian } & \multicolumn{2}{|c|}{ Muslim } \\
\hline & Number & Percent & Number & Percent \\
\hline \multicolumn{5}{|l|}{ Ever use FP methods } \\
\hline Yes & 232 & 91.7 & 144 & 57.1 \\
\hline No & 20 & 8.3 & 108 & 42.9 \\
\hline \multicolumn{5}{|c|}{ Current use of Modern Contraceptives } \\
\hline Yes & 175 & 69.4 & 99 & 39.3 \\
\hline No & 77 & 30.6 & 153 & 60.7 \\
\hline \multicolumn{5}{|l|}{ Type of Modern Contraceptive } \\
\hline Inject able & 110 & 62.9 & 65 & 65.7 \\
\hline Implants & 29 & 16.6 & 8 & 8.1 \\
\hline IUD & 7 & 4.0 & 2 & 2.0 \\
\hline Pills & 21 & 12.0 & 24 & 24.2 \\
\hline Condom & 8 & 4.6 & 0 & 0 \\
\hline \multicolumn{5}{|l|}{ Future Intention } \\
\hline Intend to use & 213 & 84.5 & 144 & 57.1 \\
\hline Not intend to use & 39 & 15.5 & 108 & 42.9 \\
\hline \multicolumn{5}{|l|}{ Reason for Non Use } \\
\hline Use of natural Method & 7 & 9.1 & 35 & 22.9 \\
\hline Desire to have more children & 29 & 37.7 & 62 & 40.5 \\
\hline Being single & 16 & 20.8 & 2 & 1.3 \\
\hline Religious prohibition & 12 & 15.6 & 43 & 28.1 \\
\hline Husband disapproval & 1 & 1.3 & 8 & 5.2 \\
\hline Drug effect & 12 & 15.6 & 3 & 2.0 \\
\hline
\end{tabular}

Table 4. Factors affecting contraceptive use of women’s by study category, North West Ethiopia, Bahir Dar City, June 2013.

\begin{tabular}{|c|c|c|c|c|c|c|}
\hline \multirow{3}{*}{ Variables } & \multicolumn{6}{|c|}{ Current Contraceptive Use } \\
\hline & \multicolumn{3}{|c|}{ Orthodox Christian } & \multicolumn{3}{|c|}{ Muslim Women } \\
\hline & Yes & No & AOR (95\% CI) & Yes & No & AOR (95\% CI) \\
\hline \multicolumn{7}{|l|}{ Age } \\
\hline $15-24$ & 66 & 17 & $11.39(3.03,42.7)$ & 44 & 43 & $5.30(1.46,19.19)$ \\
\hline $25-34$ & 86 & 36 & $1.91(0.73,4.98)$ & 41 & 51 & $3.24(1.05,10.00)$ \\
\hline $35-49$ & 23 & 24 & $1^{* *}$ & 14 & 59 & $1^{* *}$ \\
\hline \multicolumn{7}{|l|}{ Religiousity } \\
\hline Religious & 111 & 71 & $1^{* *}$ & 58 & 13 & $1^{* *}$ \\
\hline Less religious & 64 & 6 & $5.56(1.4,21.3)$ & 41 & 2 & $5(1.9,14.8)$ \\
\hline \multicolumn{7}{|l|}{ Educational Status } \\
\hline Illiterate & 17 & 18 & $1^{* *}$ & 6 & 57 & $1^{* *}$ \\
\hline Primary (Grade 1 - 8) & 53 & 28 & $2.12(3.7,32.0)$ & 34 & 45 & $12.2(8.1,14.5)$ \\
\hline Secondary ( grade 9 ) & 105 & 31 & $6.25(1.2,33.3)$ & 59 & 51 & $16.7(4.5,50)$ \\
\hline
\end{tabular}


desire to have a family size of 3 - 4 children, only 101 (40.1\%) Muslims have the desire for having three to four children.

In the current study, $100 \%$ of orthodox Christian and 99.6\% of Muslim women's knew at least one contraceptive method and its importance, which showed that Knowledge of respondents were nearly universal. The findings of 2011 DHS report also showed that Knowledge of at least one method of contraception were nearly universal among women in Ethiopia [7].

The overall prevalence of modern contraceptive use in current finding (54.3\%) was in line with the finding in Arba Minch (51.1\%) [10]. However it was higher than the finding in Hossana (47.6) [11]. This might be associated with educational status of participants. Participants in the current study and those in Arba Minch might be better educated than those in Hossana.

The prevalence of modern contraceptive use among Orthodox Christian (63.9\%) and Muslim women (36.1\%) had shown major variation. The prevalence in Orthodox Christian women was higher by $0.28,95 \%$ CI: $(0.19$, 0.36). A significance difference was also observed towards their future intension on the use of modern contraceptives (Orthodox Christian (84\%) and Muslim women (57\%)). The possible reason might be difference in educational status of orthodox Christian and Muslim Women. As mentioned in Table 1, highest number orthodox Christian (54.0\%) were completed secondary education compared with Muslim women (43.7\%).

Though Modern contraceptives are effective compared with natural methods, significant proportion of Orthodox Christian (9.1\%) and Muslim women (22.9\%) were using Natural methods [12]. This might be associated with the educational status. Those women who were using Natural methods might be the less educated ones. Fear of side effect of modern contraceptives was also another reason mentioned for the non use of modern contraceptives. Twelve (15.6\%) Orthodox Christian and Three (2\%) Muslim women had mentioned drug side effect as a reason for nonuse.

Though long acting modern contraceptives are effective and have less side effects than short acting contraceptives, the proportion of women who were using IUCD and implants were very low [12]. Majority, 110 (62.9\%) Orthodox Christian and 65 (65.7\%) Muslim women were using injectables.

This was in line with EDHS 2011 report [7]. The low use of long acting contraceptives observed in this study was in contradiction with participant's future intension. The highest proportion of orthodox Christian (84.5\%) and Muslim women 957.1\%) had intension for future use of modern contraceptives. The reason might be the knowledge of participants on long acting modern contraceptives. Women of the study area might have limited knowledge on the advantage of long acting modern contraceptives.

One of the factors which was found to have associated with Modern contraceptive use was age of participants. Participants of both groups who were in the age group between 15 - 24 and 25 - 34 were using Modern contraceptives compared with those in the age group between 35 - 49. The possible reason might be difference in the desire for having child. Women in the age group between 15 - 49 and 25 - 34 might not have the desire to have children as compared with women in the age group between 35 - 49. The probability that women get answer for their economical constraints to carry a child increases as their age increases. Women in the age group between 35 - 49 might lead stable life compared with those in other groups.

Religiousity was also identified as one of the factors which determine Modern contraceptive use. Compared with religious women, less religious women were about 5.56 times more likely to use modern contraceptive (95\% CI: 1.4, 21.3) in Orthodox Christian women and 5 times more likely to use modern contraceptives (95\% CI: 1.9, 14.8) in Muslim women. On this regard, a study conducted on the influence of religiosity on contraceptive use among Roman Catholic Women in the United States in 2007, showed that, Low Church attending women were $38 \%$ more likely to use contraceptive than high church attendants [13].

The educational status of women has appeared to be significant predictors of contraceptive use. Compared to women with no education, women who attend secondary education had greater odds of utilizing family planning service in orthodox Christian (AOR = 6.25) and Muslim women $(\mathrm{AOR}=16)$. This is true that as the level of education of women increases their level of understanding towards the complications of unintended pregnancy also increases.

\section{Conclusions}

The result of this study showed that Modern contraceptive prevalence rate among Muslim women was significantly lower than that in Orthodox Christian women. Modern Contraceptive use in both groups has shown significant association with age, education and religiosity of women. 
To reduce the problem governmental and nongovernmental organizations who are working in the area of family planning need to focus on awareness creation on modern contraceptive use with special emphasis for Muslim Women.

\section{Acknowledgements}

The authors are grateful to Bahir Dar University, GAMBY College of Medical Sciences, all study participant, data collectors and supervisors of the study.

\section{Conflict of Interests}

Authors declared that they have no conflict of interests.

\section{Author's Contribution}

D. Walelign conceptualized the research problem, designed the study, conducted field work, collected and analyzed data. A. Mekonen was involved in supervision of the field work, revision of the research design, data analysis. M. Netsere contributed in the supervision of the research, revision of the research design and data analysis, and M. Tarekegn Contributed in revision of the the document and preparation of manuscript. All authors of the manuscript have read and agreed to its content.

\section{References}

[1] USAID (2006) Achieving the Millennium Development Goals: The Contribution of Fulfilling the Unmet Need for Family Planning.

[2] Kassebaum, N.J., Bertozzi-Villa, A., Coggeshall, M.S., Shackelford, K.A., Steiner, C. and Heuton, K.R. (2014) Global, Regional, and National Levels and Causes of Maternal Mortality during 1990-2013: A Systematic Analysis for the Global Burden of Disease Study 2013. Lancet. http://www.ncbi.nlm.nih.gov/pubmed/24797575

[3] WHO (2014) Factsheet on Maternal Mortality: Media Center. http://www.who.int/mediacentre/factsheets/fs348/en/

[4] The National Academies Press (2001) The Best Intentions: Unintended Pregnancy and the Well-Being of Children and Families (1995)/Consequences of Unintended Pregnancy. 500 Fifth Street, NW, Washington DC. www.nap.edu/catalog.php?record_id=4903

[5] Alan Guttmacher Institute, Media Center News Release (2014) Unplanned Pregnancy Common Worldwide Neither Legal Status of Abortion Nor Health Risk Deters Women from Terminating Pregnancies. http://www.guttmacher.org/media/nr/abortww_nr.htmll

[6] Singh, S., Sedgh, G. and Hussain, R. (2010) Unintended Pregnancy: Worldwide Levels, Trends, and ouTcomes. Studies in Family Planning. Studies in Family Planning, 41, 241-250.

[7] Central Statistical Agency [Ethiopia] and ICF International (2012) Ethiopia Demographic and Health Survey 2011. Addis Ababa, Ethiopia and Calverton, Maryland, USA: Central Statistical Agency and ICF International.

[8] Centers for Disease Control and Prevention (2013) Reproductive Health. http://www.cdc.gov/reproductivehealth/UnintendedPregnancy/index.htm.

[9] Bahir Dar District Health Office: 2011/2012 Annual Report. Unpublished Document, Bahir Dar.

[10] Shifa, G.T. (2014) Magnitude and Correlates of Contraceptive Use among Females in Reproductive Age Group in Arba Minch Zuria Woreda. Health, 6, 1263-1276. http://dx.doi.org/10.4236/health.2014.611155

[11] Tuloro, T., Deressa, W. and Davey, G. (2006) The Role of Men in Contraceptive Use and Fertility Preference in Hossana Town, Southern Ethiopia. Ethiopian Journal of Health Development, 20, 152-159. http://www.researchgate.net/publication/239747341

[12] Bill and Melinda Gates Foundation (2012) Family Planning. https://docs.gatesfoundation.org/Documents/family-planning-strategy.pdf

[13] Victor Agadjanian; Religion and Contraception in Mozambique: A Multidimensional Analysis Center for Population Dynamics Arizona State University. https://auca.kg/uploads/Migration.../Victor_Agadjanian_CV.pdf 
Scientific Research Publishing (SCIRP) is one of the largest Open Access journal publishers. It is currently publishing more than 200 open access, online, peer-reviewed journals covering a wide range of academic disciplines. SCIRP serves the worldwide academic communities and contributes to the progress and application of science with its publication.

Other selected journals from SCIRP are listed as below. Submit your manuscript to us via either submit@scirp.org or Online Submission Portal.
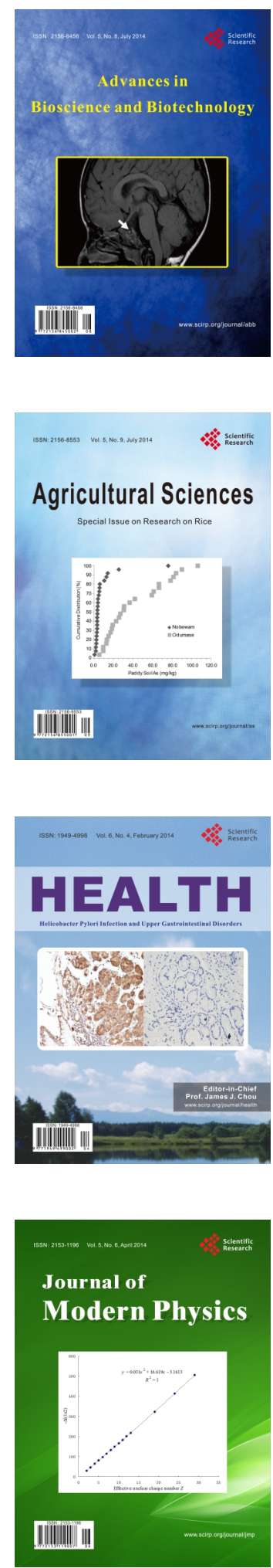
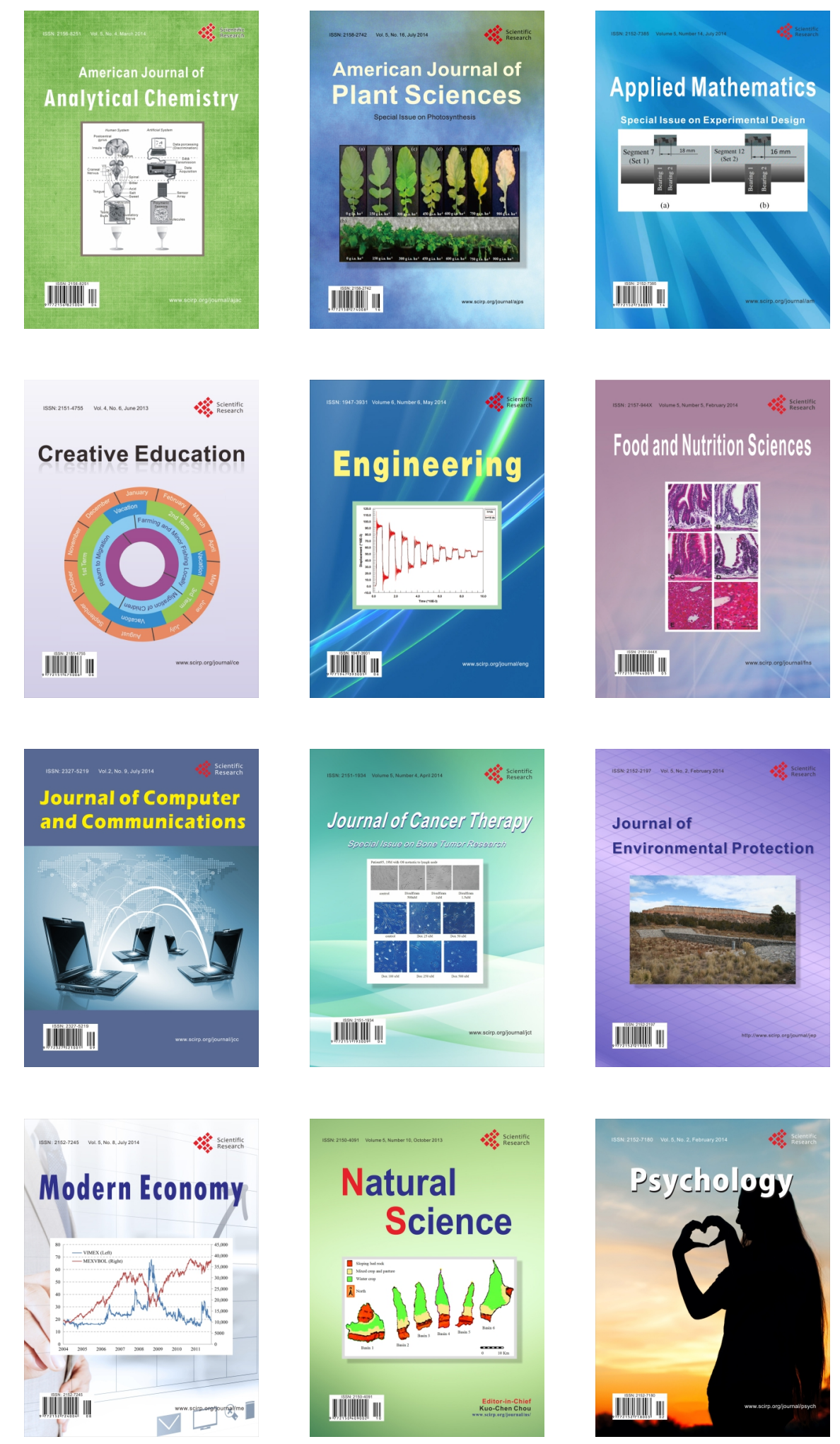